\title{
Influence of photobiomodulation therapy on the treatment of pulmonary inflammatory conditions and its impact on COVID-19
}

\author{
Daniela Bezerra Macedo ${ }^{1}$. Carla Roberta Tim ${ }^{1} \cdot$ Hueliton Wilian Kido ${ }^{2,3}$. Juliana Bezerra Macedo ${ }^{1}$ \\ Cintia Cristina Santi Martignago ${ }^{2}$. Ana Claudia Muniz Renno ${ }^{2} \cdot$ Glauber Bezerra Macedo $^{3} \cdot$ Lívia Assis $^{1}$ (i)
}

Received: 17 May 2021 / Accepted: 20 October 2021 / Published online: 25 October 2021

(c) The Author(s), under exclusive licence to Springer-Verlag London Ltd., part of Springer Nature 2021

\begin{abstract}
We are currently facing a pandemic that continuously causes high death rates and has negative economic and psychosocial impacts. Therefore, this period requires a quick search for viable procedures that can allow us to use safe and non-invasive clinical tools as prophylactic or even adjuvant methods in the treatment of COVID-19. Some evidence shows that photobiomodulation therapy (PBMT) can attenuate the inflammatory response and reduce respiratory disorders similar to acute lung injury (ALI), complications associated with infections, such as the one caused by the new Coronavirus (SARS-CoV-2). Hence, the aim of the present study was to evaluate the influence of PBMT (infrared low-level laser therapy) on the treatment of ALI, one of the main critical complications of COVID-19 infection, in an experimental model in rats. Twenty-four male Wistar rats were randomly allocated to three experimental groups $(n=8)$ : control group (CG), controlled ALI (ALI), and acute lung injury and PBM (ALIP). For treatment, a laser equipment was used $(808 \mathrm{~nm} ; 30 \mathrm{mw} ; 1.68 \mathrm{~J})$ applied at three sites (anterior region of the trachea and in the ventral regions of the thorax, bilaterally) in the period of 1 and $24 \mathrm{~h}$ after induction of ALI. For treatment evaluation, descriptive histopathological analysis, lung injury score, analysis of the number of inflammatory cells, and expression of interleukin $1 \beta$ (IL-1 $\beta$ ) were performed. In the results, it was possible to observe that the treatment with PBMT reduced inflammatory infiltrates, thickening of the alveolar septum, and lung injury score when compared to the ALI group. In addition, PBMT showed lower immunoexpression of IL-1 $\beta$. Therefore, based on the results observed in the present study, it can be concluded that treatment with PBMT (infrared low-level laser therapy) was able to induce an adequate tissue response capable of modulating the signs of inflammatory process in ALI, one of the main complications of COVID-19.
\end{abstract}

Keywords Photobiomodulation $\cdot$ Low-level laser $\cdot$ Acute lung injury $\cdot$ COVID-19

\section{Introduction}

Currently, with more than 219 million confirmed cases and more than 4.54 million deaths across the world [1], the new Coronavirus (named by Severe Acute Respiratory Syndrome Coronavirus 2 - SARS-CoV-2), the etiological agent of

Lívia Assis

livinha_fisio@yahoo.com.br

1 Scientific Institute and Technological Department, University Brazil (UB), Sao Paulo-Itaquera, SP, Brazil

2 Department of Biosciences, Federal University of São Paulo (UNIFESP), Santos, SP, Brazil

3 Postgraduate Program in Biophotonics Applied To Health Sciences, Universidade Nove de Julho (UNINOVE), Sao Paulo, SP, Brazil
Coronavirus Disease 2019 (COVID-19), has become a worldwide public health issue due to its serious health consequences for infected individuals and the negative psychosocial and economic impacts related to COVID-19 [2].

SARS-CoV-2 primarily targets the respiratory system, which can cause health problems with mild symptoms in the upper respiratory tract, even severe respiratory syndrome or death [3]. Initial reports pointed out that acute respiratory disorder was the leading cause of death from coronavirus in China, with acute lung injury (ALI) and acute respiratory distress syndrome (ARDS) being some of the critical complications of COVID-19 infection [4].

Overall, ALI/ARDS are characterized by the occurrence of lung tissue damage, followed by rapid onset of respiratory failure in individuals affected by the disease [4-7]. In ALI/ARDS, it is possible to verify diffuse alveolar damage 
(DAD), which is identified mainly by the presence of intraalveolar exudate (represented by the formation of hyaline membrane-mixture of protein exudate, surfactant, and cellular debris) [8-10]. In addition to hyaline membrane, other pathological markers for DAD include the presence of inflammation, hemorrhage, and damage to alveolar epithelial cells (type I and II pneumocytes) [8].

In DAD, there is a migration of inflammatory cells to the lung tissue, predominantly represented by neutrophils. Excessive and/or prolonged activation of these cells contributes to the destruction of the basement membrane and increase in permeability of the alveolar-capillary barrier, resulting in interstitial and alveolar edema $[7,11,12]$. Neutrophils release several pro-inflammatory mediators, such as tumor necrosis factor type $\alpha$ (TNF- $\alpha$ ) and interleukins (IL) IL-1 $\beta$, IL-6, and IL-8, which act to intensify the inflammatory response, promoting chemotaxis, and activation of new inflammatory cells and releasing oxidants, proteases, leukotrienes, and other pro-inflammatory molecules that contribute to pulmonary parenchymal damage [13]. The inflammatory process, once installed, leads to the death of pneumocytes and inactivation of surfactants, decreasing lung compliance and contributing to the development of respiratory failure [11].

Since the restoration of normal pulmonary function is based on the reduction of edema, clearance of inflammatory cells, and repair of the alveolar barrier, conventional treatments for ALI/ARDS such as low volume mechanical ventilation, prone position, and extracorporeal membrane oxygenation, in addition to several pharmacological strategies, are necessary, but they are not effective enough to restore normal lung function [11]. Thereby, innovative therapies need to be developed in order to complement these conventional treatments, aiming mainly to attenuate the inflammatory process and stimulate the mechanisms of lung parenchyma repair.

Among the resources studied, photobiomodulation therapy (PBMT) with low-intensity laser and light-emitting diodes (LEDs), has been identified as a promising tool for the treatment of inflammatory lung diseases [14-21]. The effects of PBMT are based on the absorption of light photons by cytochrome c oxidase in cell mitochondria, causing a photochemical cascade stimulus that increases the production of reactive oxygen species (ROS), adenosine triphosphate (ATP), and induction of factors of transcription, responsible for regulating the cell cycle, protein synthesis, and important enzymes [21]. Experimental data showed that PBMT with low-intensity laser (mainly with red spectrum light) is able to reduce airway edema, pulmonary inflammation, acute respiratory disorders, pulmonary fibrosis, and other respiratory complications, by decreasing the migration of neutrophils to the lung tissue and reducing the synthesis of pro-inflammatory cytokines (IL-1 $\beta$, IL-6, TNF- $\alpha$ ) and collagen deposition [14, 22-26].

According to the results found, low-level laser is considered a promising strategy for the treatment of ALI/ARDS, which represents a major advance for public health in the current world scenario, since ALI/ARDS is one of the main complications caused by COVID-19 infection $[4,21]$.

Although there are studies showing the positive effect of PBMT on pulmonary changes, there is a lack of studies in the literature investigating the effect of this resource, especially with the use of light in the infrared spectrum, in the treatment of pulmonary disorders such as ALI. Thereby, it raised the hypothesis that PBMT with infrared laser could modulate the resolution of the inflammatory process and favor the reestablishment of pulmonary homeostasis, constituting an appropriate and effective treatment to be used in clinical practice. Thus, the objective of the present study was to evaluate the influence of PBMT, at infrared wavelength, in an experimental rat model of ALI, focusing on histopathological analysis and secretion of inflammatory cytokines.

\section{Methods}

\section{Experimental design}

Adult male Wistar rats (Rattus norvegicus), weighing $\pm 272 \mathrm{~g}, 6$ weeks old were used in the present study. Animals were placed in plastic cages with sawdust bedding, with one animal per cage and were allowed to move freely in the cages with free access to commercial food and water. The room had a 12-h dark/light cycle and a controlled temperature $\left(24 \pm 2{ }^{\circ} \mathrm{C}\right)$. The present study was approved by the Animal Care Committee guidelines at the Universidade Brasil (protocol 2,000,090), and it was conducted according to the Guiding Principles for the Use of Laboratory Animals.

Twenty-four rats were randomly divided into 3 groups ( $n=8$ per group): control group (CG): animals without any intervention; control acute lung injury (ALI): acute lung injured animals without treatment; and acute lung injury and PBM (ALIP): acute lung injured animals treated with PBM.

\section{Acute lung injury experimental model}

Acute lung injury was produced by cecal ligation and puncture (CLP) as previously described ${ }^{19}$. For the surgical procedure, rats received intra-peritoneal anesthesia with $40 \mathrm{mg} / \mathrm{kg}$ ketamine (Dopalen, Vetbrands, São Paulo, Brazil) and $20 \mathrm{mg} / \mathrm{kg}$ xylazine (Anasedan, Vetbrands, São Paulo, Brazil). The surgical area was shaved, then sterilized and draped in sterile fashion. Afterwards, a midline laparotomy was performed, and the cecum was ligated at its base and punctured twice with a 22 -gauge $(0.7176 \mathrm{~mm})$ needle. The 
cecum was then returned to the peritoneal cavity and muscles, and skin were sutured. Animals were resuscitated with $10 \mathrm{ml}$ of $0.9 \%$ sterile saline solution administered subcutaneously and were housed in single plastic cages and were given appropriate postoperative care. In order to minimize post-operative discomfort, the animals received analgesia $(0.2 \mathrm{mg} / \mathrm{kg}$ buprenorfiine - Temgesic; Reckitt Benckiest Healt Care Ltd. Schering-Plow, Hoddesdon, UK) directly after the operation and subcutaneously for two days after surgery.

\section{PBMT protocol}

A gallium-aluminum-arsenide (GaAlAs) diode laser (Photon Laser II, DMC® equipment Ltda, SP, São Carlos, Brazil) was used in the following parameters: continuous irradiation mode, $808 \mathrm{~nm}$ wavelength, $30 \mathrm{~mW}$ power output, $56 \mathrm{~s}$ irradiation time, $0.028 \mathrm{~cm}^{2}$ spot area, dose $60 \mathrm{~J} / \mathrm{cm}^{2}$, irradiance $1.07 \mathrm{~W} / \mathrm{cm}^{2}$, and $1.68 \mathrm{~J}$ total energy per point/section. The laser irradiation was performed daily for two consecutive days, starting immediately after the surgery ( 2 sessions) at 3 points: anterior region of the trachea and on ventral regions of the chest bilaterally (just below the ribs), through the punctual contact technique.

Three days after surgery, all animals were euthanized individually by anesthesic overdose (twofold anesthesic dose) and the lung of each animal was removed for analysis.

\section{Histological procedures and qualitative evaluation}

After surgical resection of the specimens of all experimental group, the right lung was washed immediately with saline and fixed in 10\% buffered formalin (Merck, Darmstadt, Germany) for $12 \mathrm{~h}$, followed by dehydration in a graded series of ethanol and embedding in paraffin. Thin Sects. $(3 \mu \mathrm{m})$ in the longitudinal axis of the lung were obtained using a microtome (Leica Microsystems SP 1600, Nussloch, Germany). Sections of each specimen were stained with hematoxylin and eosin (HE) (Merck) and examined using light microscopy (AxioVision 4,7; Carl Zeiss ${ }^{\circledR}$, Germany). Two experienced observers (LA and DM) performed the qualitative evaluation ${ }^{20}$ in a blinded manner.

\section{Lung injury scoring system}

The lung injury in all samples was assessed and compared according to the American Thoracic Socity [21]. Sample was assessed on a scale of $0-2$ for each of the following criteria: (A) neutrophil in the alveolar space, (B) neutrophil in the interstitial space, (C) hyaline membranes, (D) proteinaceous debris filling the airspaces, and (e) alveolar septal thickening. The final lung injury score was derived from the following calculation: Score $=[(20 \times A)+(14 \times B)+(7 \times C)$
$+(7 \times D)+2 \times E)] /($ number of fields $\times 100)$. Increased score indicates less lung injury. Digital images of the $400 \times$ magnification were captured by optical microscope (Carl Zeiss, Oberkochen, Germany). All variables were measured in 5 fields in each animal, and two experienced observers (LA and WA) performed the scoring in a blinded manner.

\section{Morphometric evaluation of inflammatory cells}

The same image analysis technique used to evaluate lung injury (in five preselected areas) was applied to determine the number of inflammatory cells (polymorphonuclear and mononuclear). The cells were counted using Image $\mathbf{J}$ software 1.4 program (Research Services Branch, Nacional Institutes of Health - NIH, EUA). Two experienced observers (LA and WA) performed the scoring in a blinded manner.

\section{Immunohistochemistry analysis}

For IL-1 $\beta$ expression analysis, the paraffin was removed with xylene from serial sections of $5 \mu \mathrm{m}$. After this procedure, the sections were rehydrated in graded ethanol and pretreated in a microwave with $0.01 \mathrm{M}$ citric acid buffer ( $\mathrm{pH}$ 6) for 3 cycles of $5 \mathrm{~min}$ each at $850 \mathrm{~W}$ for antigen retrieval. Subsequently, the material was pre-incubated with $0.3 \%$ hydrogen peroxide in phosphate-buffered saline (PBS) solution for $5 \mathrm{~min}$ to inactivate the endogenous peroxidase and then blocked with 5\% normal goat serum in PBS solution for $10 \mathrm{~min}$. The specimens were incubated with anti- IL-1 $\beta$ polyclonal primary antibody (Santa Cruz Biotechnology, USA) at a concentration of 1:200. Incubation was performed overnight at $4{ }^{\circ} \mathrm{C}$ in the refrigerator and followed by two washes in PBS for $10 \mathrm{~min}$. Afterwards, the sections were incubated with biotin conjugated secondary antibody anti-rabbit IgG (Vector Laboratories, Burlingame, CA, USA) at a concentration of 1:200 in PBS for $1 \mathrm{~h}$. The sections were washed two times with PBS followed by the application of avidin biotin complex conjugated to peroxidase for $45 \mathrm{~min}$. The visualization of the bound complexes was realized by the application of a $0.05 \%$ solution of 3-3'-diaminobenzidine solution and counterstained with Harris Hematoxylin. Finally, for control analyses of the antibodies, the serial sections were treated with rabbit IgG at a concentration of 1:200 instead of the primary antibody. Furthermore, internal positive controls were performed with each staining bath. Digital images of the $200 \times$ magnification were captured by optical microscope. The results were evaluated both qualitatively (presence of the immunomarkers) and semi quantitatively according to a previously described scoring scale from 1 to $4(1=$ absent, $2=$ weak, $3=$ moderate, and $4=$ intense for immunohistochemical analysis) [27]. Two experienced observers (LA and $\mathrm{CT})$ performed the scoring in a blinded manner. 


\section{Statistical analysis}

Data are expressed as the mean \pm standard error of the mean (SEM). Shapiro-Wilk's and Levene's tests were applied to evaluate the normality and homogeneity of the results, respectively. For the variables that exhibited normal distribution, comparisons between experimental groups were performed by analysis of variance (one-way ANOVA), and the Tukey post-test used to compare individual groups. For the variables that exhibited non-normal distribution, Kruskal-Wallis test was used. A $p$ value $<0.05$ was considered significant. All analyzes were performed using a GraphPad Prism 6.0 (GraphPad Software, San Diego CA, USA).

\section{Results}

\section{General observation of the experimental animals}

The animals recovered uneventfully from the acute lung injury induction. No signs of macroscopic adverse tissue responses were observed during the experimental period.

\section{Histological descriptive analysis}

Representative images of lung tissue cuts are shown in Fig. 1. In histopathological analysis, the GC group revealed alveolar sacs lined by simple epithelial pavement epithelium and alveolar macrophages. The ALI and ALIP groups demonstrated morphological changes characterized by intense cellular inflammatory infiltrate, edema in the interstitial area, and thickening of the alveolar septum. However, in the ALIP group, less thickening of the alveolar septum and reduced inflammatory infiltrates were observed in relation to the ALI group.

\section{Lung injury score}

The values of the lung injury score are shown in Fig. 2. It was possible to observe a significantly higher score in the ALI groups compared to the ALIP $(p=0.0041)$ and CG $(p=0.039)$. No difference was observed between the GC and ALIP groups.

\section{Morphometric analysis of inflammatory cells number}

The results of the morphometric analysis of the number of inflammatory cells are shown in Fig. 3. A significantly higher number of inflammatory cells was observed in the ALI groups when compared to the GC $(p=0.0036)$ and ALIP $(p=0.0284)$ groups. No additional differences were observed.

\section{Immunohistochemistry analysis - IL-1 $\beta$ expression}

The immunohistochemistry results revealed positive IL-1 $\beta$ staining in the inflammatory cells in both ALI groups (ALI and ALIP; Fig. 4a). However, the semi-quantitative analysis showed a lower IL-1 $\beta$ expression in the GC $(p<0.0001)$ and $\operatorname{ALIP}(p=0.0341)$ when compared to ALI (Fig. 4b).

\section{Discussion}

The present study aimed to evaluate the influence of PBMT at infrared wavelength on the acute phase of ALI in an experimental model in rats. The main results showed that the laser treatment was effective in attenuating inflammatory infiltrate, reducing thickening of the alveolar septum, and lung injury score. In addition, PBMT reduced immunoexpression of pulmonary IL- $1 \beta$.

The effectiveness of PBMT in the treatment of respiratory tract disorders has been demonstrated since the time of the studies by Finsen (1901), where the author showed significantly faster recovery of patients with pulmonary infections after undergoing the treatment with phototherapy. Furthermore, empirical practice has shown that light has positive effects on the treatment of asthma, bronchitis, and acute and chronic pneumonias [28-30]. Although there is evidence that PBMT has led to the rehabilitation of these patients, there is still a gap in the literature regarding the mechanisms
Fig. 1 Representative photomicrographs of morphological analysis of acute lung injury cross sections. Alveolar septum (asterisks); presence of inflammatory process (arrow). Control group (CG); control acute lung injury (ALI); acute lung injury and PBM (ALIP). (stain: HE; scale bar: $50 \mu \mathrm{m})$

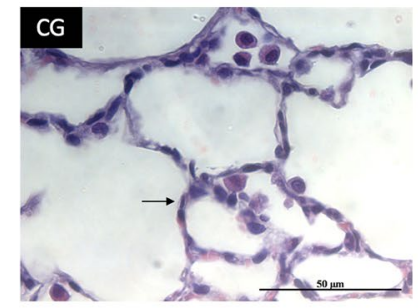

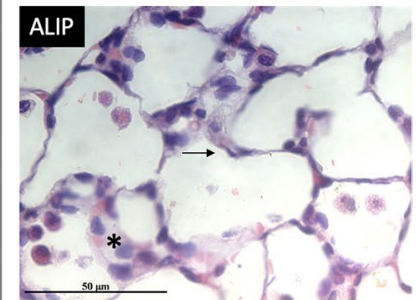


Fig. 2 Lung injury scoring system analysis. Control group (CG); control acute lung injury (ALI); acute lung injury and PBM (ALI). *CG versus ALI $(p=0.039)$; \#ALIP versus ALI $(p=0.0041)$

Fig. 3 Morphometric analysis of inflammatory cells number. Control group (CG); control acute lung injury (ALI); acute lung injury and PBM (ALI). *CG versus ALI $(p=0.0036)$; \#ALIP versus ALI $(p=0.0284)$
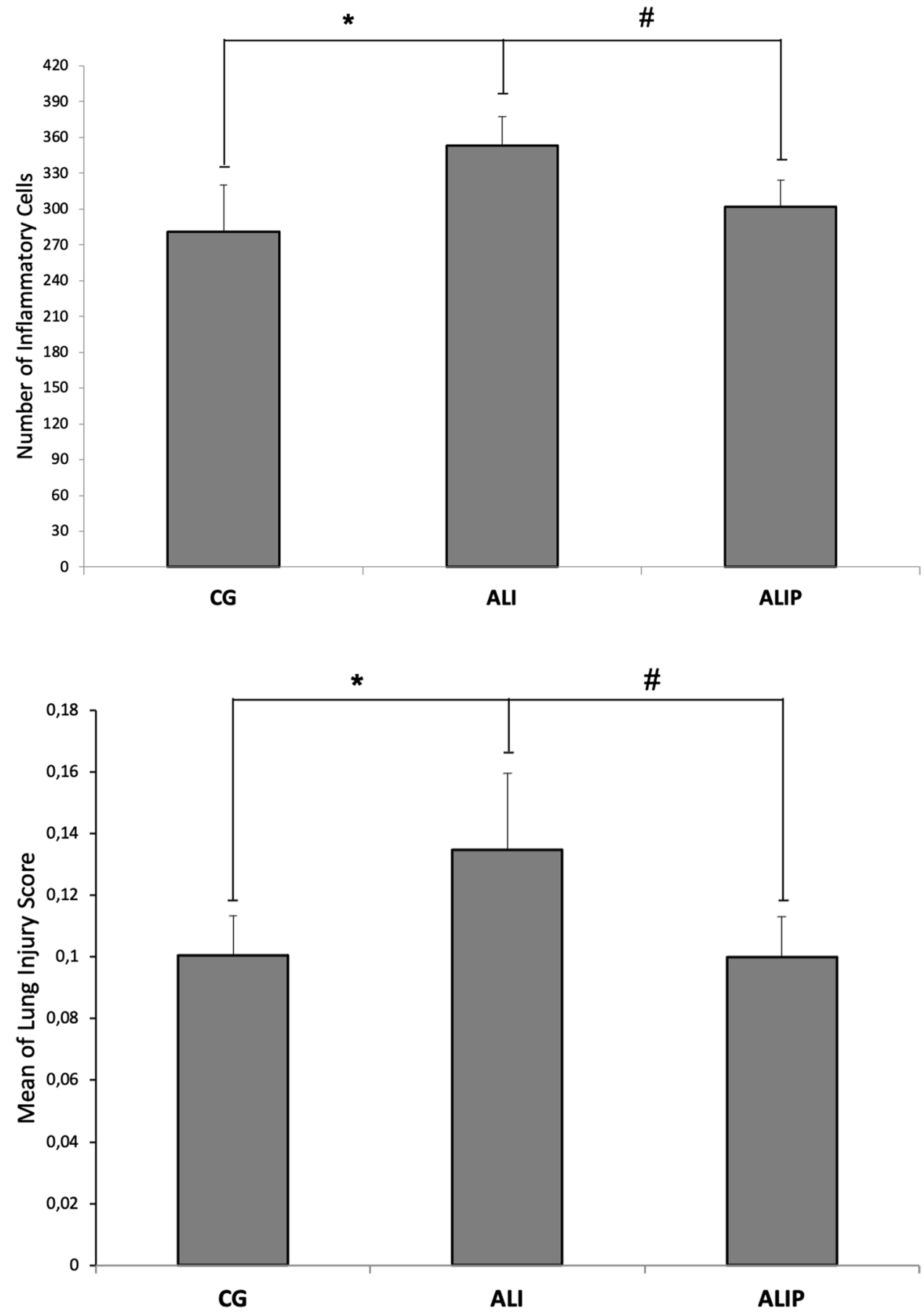

of action and ideal treatment parameters, especially in view of the modulation of the inflammatory process resulting from ALI.

ALI remains a prevalent clinical challenge, and the methods used for treatment are often still poorly understood. In humans, ALI is defined based on the well-defined set of clinical parameters developed by acute onset, radiological evidence of bilateral, diffuse pulmonary infiltrates, and a $\mathrm{PaO} 2 / \mathrm{FIO} 2$ ratio of less than 300 [31]. However, for the evaluation of ALI induced in an animal model, it is not practical to use these same criteria, as the parameters used are not directly translated, since the devices necessary for these measurements are costly and difficult to access, in addition to the fact that these measurements may be incompatible with the design of many experimental systems. As an alternative approach to the diagnosis of ALI in animals, histopathological criteria similar to those observed in humans with ALI have been used and the pathological correlates of 
A)
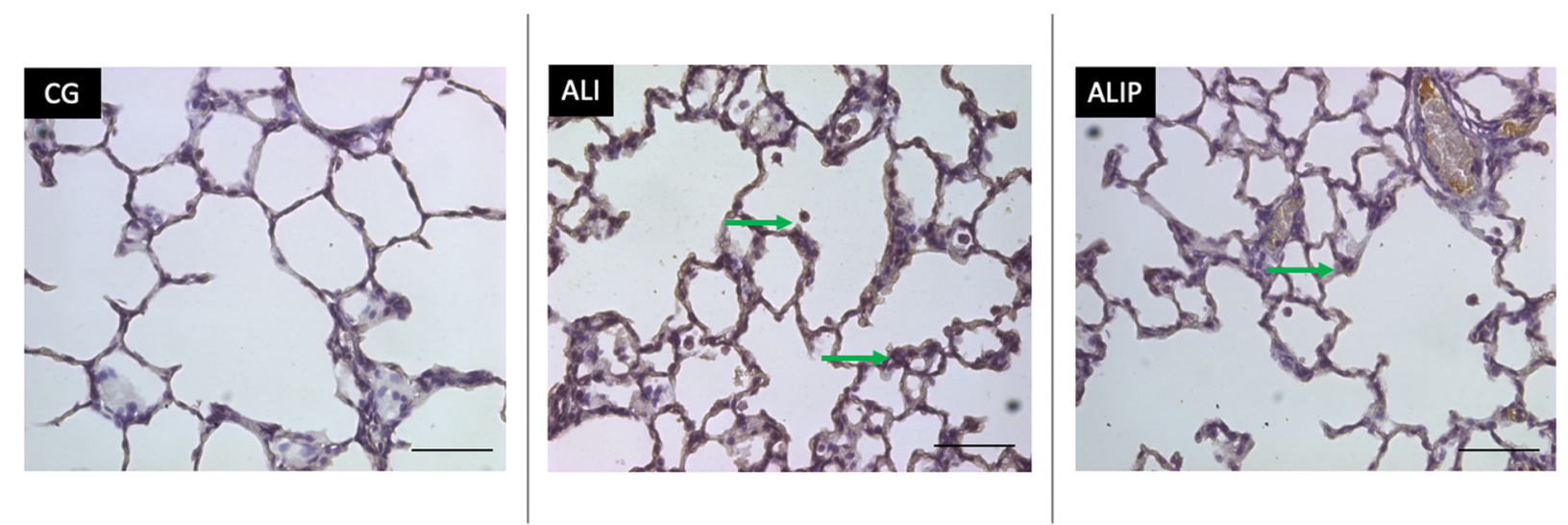

B)

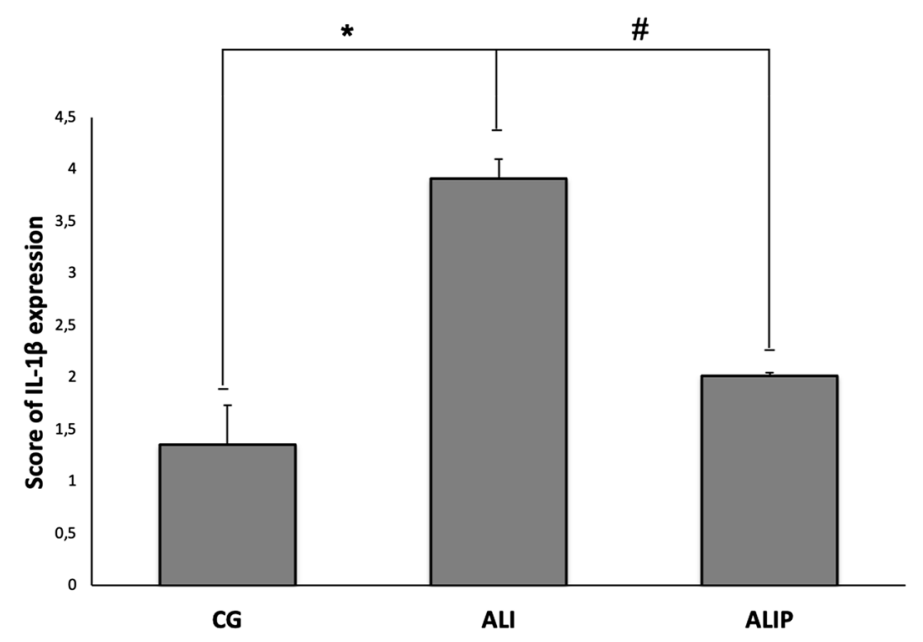

Fig. 4 a Representative sections of IL-1 $\beta$ immunohistochemistry. Immunolabeled inflammatory cells (arrow). b Results of semi-quantitative analysis of the IL- $1 \beta$ expression. Control group (CG); con-

trol acute lung injury (ALI); acute lung injury and PBM (ALI). *CG versus ALI $(p<0.0001)$; \#ALIP versus ALI $(p=0.0341)$. Scale bar: $20 \mu \mathrm{m}$

ALI are defined by diffuse alveolar damage, characterized by inflammatory infiltrates, thickened alveolar septa, and deposition of hyaline membranes [32].

The histological analysis of the present study is consistent with the diagnostic criteria of ALI established by MatuteBello et al. [32], since the animals that were submitted to the CLP model presented morphological changes characterized by intense inflammatory infiltrate, interstitial edema, and thickening of the alveolar septum. Similar results were observed in the study by Yin et al. [33], which verified the occurrence of a serious injury in the lung tissue, characterized by diffuse alveolar hemorrhage, thickening of the alveolar walls, and an increase in inflammatory cells, $48 \mathrm{~h}$ after CLP induction. Interestingly, in the present study, after treatment with PBMT, using laser at infrared wavelength in the lower airways, the animals showed reduced inflammatory infiltrates and less thickening of the alveolar septum when compared to the untreated ones. Furthermore, it is known that the increase in inflammatory cells, especially neutrophils, which are responsible for this loss of independent vascular integrity in ALI. When an insult occurs,

neutrophils accumulate in the pulmonary microvasculature and are activated leading to the release of several toxic mediators, including proteases, reactive oxygen species, pro-inflammatory cytokines, and pro-coagulant molecules, which results in increased vascular permeability and subsequent installation of edema [7, 34]. In the morphometric analysis of the number of inflammatory cells performed in the present study, a smaller number of them were observed in the group treated with PBMT. These findings corroborate those authors who affirm that photochemical stimulus induced by PBMT by red wavelength can modulate the pulmonary inflammatory process in ALI experimental models $[35,36]$. Based on these findings, it appears that PBMT at red and infrared wavelengths were able to reduce the mediators and signs of inflammation of the lung tissue, attenuating DAD.

Moreover, regarding lung injury score proposed by the American Thoracic Society [31], it was observed that the animals treated with PBMT had lower scores when compared to the ALI group. It is important to highlight that through these histopathological findings of the present 
study, it can be suggested that therapy with PBMT was efficient in attenuating damage to the pulmonary parenchyma observed in the acute phase of ALI and consequent additional complications.

As previously mentioned, the pathophysiology of ALI is associated with a significant increase in inflammatory cytokines. Biomarkers involved in the inflammatory and coagulation cascades found in the epithelium and endothelium predict morbidity and mortality in ALI, with emphasis on IL-1 $\beta$, activated by several inflammatory cells. It is known that the activation of IL- $1 \beta$ generates a significant increase in the synthesis of other pro-inflammatory factors, thereby contributing to the severity of DAD. In the present study, it was observed that PBMT at infrared wavelength reduced local protein expression of pro-inflammatory cytokines IL-1 $\beta$, inferring that PBMT promoted the modulation of the inflammatory response and attenuated the progression of the severity of the lung injury. These findings are in accordance with Mafra de Lima et al. [22] and Lima et al. [23], that using an experimental model of pulmonary inflammation by LPS instillation in rats, they demonstrated that red laser $(685 \mathrm{~nm}), 24 \mathrm{~h}$ after induction of inflammation, was able to minimize pulmonary inflammation and endothelial injury, which was evidenced by a reduction in vascular permeability, pulmonary edema, activation of neutrophils in the lung tissue, and decreased TNF- $\alpha$ and IL-1 $\beta$. Recently, da Cunha et al. [25] showed that PBMT with a red laser $(660 \mathrm{~nm})$ significantly minimized the number of inflammatory cells and secretion of pro-inflammatory cytokines, such as IL- $1 \beta$, IL-6, and TNF- $\alpha$ in bronchoalveolar lavage fluid (BAL) in an experimental model of chronic obstructive pulmonary disease.

Thus, based on the results observed in the present study, it can be suggested that laser at infrared wavelength was able to induce an adequate tissue response capable of modulating the signs of the existing acute pulmonary inflammatory process. The attenuation of the recruitment of inflammatory cells proven in the present study and the reduction of IL-1 $\beta$ is probably associated with the reduction of damages in the lung parenchyma, and, consequently, attenuation of pulmonary damages that occur during ALI.

Thereby, this study provides important information about the effect of PBMT with laser at infrared wavelength as an adjunct to the treatment of ALI. In addition, as part of the ongoing effort to mobilize all clinical tools with the potential to alleviate the symptoms caused by COVID-19, this study offers compelling reasons for exploring the potential effects of infrared wavelengths in the ongoing fight against diseases caused by SARS-CoV-2. However, it is necessary to investigate, through controlled and randomized experimental and clinical studies, what are the best parameters and light spectra to be used to provide the best results for the treatment of inflammatory lung diseases, especially those caused by the new coronavirus.

\section{Conclusion}

In this study, we present evidence that only two applications of PBMT with laser at infrared wavelength are able to reduce inflammation in an experimental model of ALI, one of the main critical complications of COVID-19 infection. This phenomenon occurs by attenuating the influx of inflammatory cells and inhibiting secretion of pro-inflammatory cytokine, leading to a decrease in lung damage. This type of experimental evidence is necessary for the design of other clinical trials involving the use of PBMT in respiratory disorders similar to complications associated with coronavirus infections.

\section{Declarations}

Ethical approval This study was approved by the Ethics Committee on the Use of Animal under number 2000090 and conducted according to the international norms of ethics on animal experimentation (National Researche Council, 1996).

Competing interest The authors declare no competing interests.

\section{References}

1. WHO: Official COVID update. [Cited 2020, June 27th]. Available at: https://www.paho.org/bra.

2. Rando HM, Bennett TD, Byrd JB, Bramante C, Callahan TJ, Chute CG, Davis HE, Deer R, Gagnier J, Koraishy FM, Liu F, McMurry JA, Moffitt RA, Pfaff ER, Reese JT, Relevo R, Robinson PN, Saltz JH, Solomonides A, Sule A, Topaloglu U, Haendel MA (2021) Challenges in defining long COVID: striking differences across literature, Electronic Health Records, and patient-reported information. medRxiv [Preprint]. 2021.03.20.21253896. https:// doi.org/10.1101/2021.03.20.21253896

3. Badraoui R, Alrashedi MM, El-May MV, Bardakci F (2020) Acute respiratory distress syndrome: a life threatening associated complication of SARS-CoV-2 infection inducing COVID-19. J Biomol Struct Dyn 5:1-10. https://doi.org/10.1080/07391102.2020.18031 39

4. Guo YR, Cao QD, Hong ZS, Tan YY, Chen SD, Jin HJ, Tan KS, Wang DY, Yan Y (2020) The origin, transmission and clinical therapies on coronavirus disease 2019 (COVID-19) outbreak an update on the status. Mil Med Res 7(1):11. https://doi.org/10. 1186/s40779-020-00240-0

5. Ashbaugh DG, Bigelow DB, Petty TL, Levine BE (1967) Acute respiratory distress in adults. Lancet 2(7511):319-323. https://doi. org/10.1016/s0140-6736(67)90168-7

6. Hughes KT, Beasley MB (2017) Pulmonary manifestations of acute lung injury: more than just diffuse alveolar damage. Arch Pathol Lab Med 141(7):916-922. https://doi.org/10.5858/arpa. 2016-0342-RA 
7. Mowery NT, Terzian WTH, Nelson AC (2020) Acute lung injury. Curr Probl Surg 57(5):100777. https://doi.org/10.1016/j.cpsurg. 2020.100777

8. Kao KC, Hu HC, Chang CH, Hung CY, Chiu LC, Li SH, Lin SW, Chuang LP, Wang CW, Li LF, Chen NH, Yang CT, Huang CC, Tsai YH (2015) Diffuse alveolar damage associated mortality in selected acute respiratory distress syndrome patients with open lung biopsy. Crit Care 19(1):228. https://doi.org/10.1186/ s13054-015-0949-y

9. King TC (2007) Respiratory tract and pleura. Elsevier's Integrated Pathology 197-216. https://doi.org/10.1016/B978-0-323-04328-1. 50014-0

10. Matthay MA, Zemans RL, Zimmerman GA et al (2019) Acute respiratory distress syndrome. Nat Rev Dis Primers 5:18. https:// doi.org/10.1038/s41572-019-0069-0

11 Ware LB, Matthay MA (2000) The acute respiratory distress syndrome. N Engl J Med 342(18):1334-49. https://doi.org/10.1056/ NEJM200005043421806

12. Johnson ER, Matthay MA (2010) Acute lung injury: epidemiology, pathogenesis, and treatment. J Aerosol Med Pulm Drug Deliv 23(4):243-252. https://doi.org/10.1089/jamp.2009.0775

13. Lang JD, McArdle PJ, O'Reilly PJ, Matalon S (2002) Oxidantantioxidant balance in acute lung injury. Chest 122(6 Suppl):314S320S. https://doi.org/10.1378/chest.122.6_suppl.314s

14. da Miranda SC, Peres LM, Brochetti RA, Braga T, Vitoretti LB, Saraiva Câmara NO, Damazo AS, Ligeiro-de-Oliveira AP, Chavantes MC, Lino-Dos-Santos-Franco A (2015) Low level laser therapy reduces the development of lung inflammation induced by formaldehyde exposure. PLoS ONE 10(11):e0142816. https:// doi.org/10.1371/journal.pone.0142816

15. Silva MR, Peres LM, Braga TT, Barioni ÉD, de Oliveira DS, Ratto Tempestini Horliana AC, Câmara NO, Marcourakis T, Farsky SH, Lino-Dos-Santos-Franco A (2016) Photobiomodulation therapy decreases oxidative stress in the lung tissue after formaldehyde exposure: role of oxidant/antioxidant enzymes. Mediators Inflamm 2016:9303126. https://doi.org/10.1155/2016/9303126

16. Landyshev IuS, Avdeeva NV, Goborov ND, Krasavina NP, Tikhonova GA, Tkacheva SI (2002) Effektivnost' nizkointensivnogo lazernogo izlucheniia i nedokromila natriia pri kompleksnom lechenii bol'nykh bronkhial'noŭ astmoŭ [Efficacy of low intensity laser irradiation and sodium nedocromil in the complex treatment of patients with bronchial asthma]. Ter Arkh 74(3):25-28

17. Aimbire F, Albertini R, Pacheco MT, Castro-Faria-Neto HC, Leonardo PS, Iversen VV, Lopes-Martins RA, Bjordal JM (2006) Low-level laser therapy induces dose-dependent reduction of TNFalpha levels in acute inflammation. Photomed Laser Surg 24(1):33-37. https://doi.org/10.1089/pho.2006.24.33

18. Oliveira MC Jr, Greiffo FR, Rigonato-Oliveira NC, Custódio RW, Silva VR, Damaceno-Rodrigues NR, Almeida FM, Albertini R, Lopes-Martins RÁ, de Oliveira LV, de Carvalho PT, Ligeiro de Oliveira AP, Leal EC Jr, Vieira RP (2014) Low level laser therapy reduces acute lung inflammation in a model of pulmonary and extrapulmonary LPS-induced ARDS. J Photochem Photobiol B 134:57-63. https://doi.org/10.1016/j.jphotobiol.2014.03.021

19. Silva VR, Marcondes P, Silva M, Villaverde AB, Castro-FariaNeto HC, Vieira RP, Aimbire F, de Oliveira AP (2014) Low-level laser therapy inhibits bronchoconstriction, Th2 inflammation and airway remodeling in allergic asthma. Respir Physiol Neurobiol 194:37-48. https://doi.org/10.1016/j.resp.2014.01.008

20. da-Palma-Cruz M, Silva RF, Monteiro D, Rehim HMMA, Grabulosa CC, Oliveira APL, Lino-Dos-Santos-Franco A (2019) Photobiomodulation modulates the resolution of inflammation during acute lung injury induced by sepsis. Lasers Med Sci 34(1):191199. https://doi.org/10.1007/s10103-018-2688-1

21. Vetrici MA, Mokmeli S, Bohm AR, Monici M, Sigman AS (2021) Evaluation of adjunctive photobiomodulation (PBMT) for COVID-19 pneumonia via clinical status and pulmonary severity indices in a preliminary trial. J Inflamm Res 14:965979. https://doi.org/10.2147/JIR.S301625

22. Mafra de Lima F, Villaverde AB, Salgado MA, Castro-FariaNeto HC, Munin E, Albertini R, Aimbire F (2010). Low intensity laser therapy (LILT) in vivo acts on the neutrophils recruitment and chemokines/cytokines levels in a model of acute pulmonary inflammation induced by aerosol of lipopolysaccharide from Escherichia coli in rat. Journal of photochemistry and photobiology. B, Biology, 101(3), 271-278. https://doi.org/ 10.1016/j.jphotobiol.2010.07.012

23. de Lima FM, Moreira LM, Villaverde AB, Albertini R, Castro-Faria-Neto HC, Aimbire F (2011) Low-level laser therapy (LLLT) acts as cAMP-elevating agent in acute respiratory distress syndrome. Lasers Med Sci 26(3):389-400. https://doi.org/ 10.1007/s10103-010-0874-x

24. Brochetti RA, Leal MP, Rodrigues R, da Palma RK, de Oliveira LVF, Horliana ACRT, Damazo AS, de Oliveira APL, Paula Vieira R, Lino-Dos-Santos-Franco A (2017) Photobiomodulation therapy improves both inflammatory and fibrotic parameters in experimental model of lung fibrosis in mice. Lasers Med Sci 32(8):1825-1834. https://doi.org/10.1007/s10103-017-2281-z

25. da Cunha MG, Vitoretti LB, de Brito AA, Alves CE, de Oliveira NCR, Dos Santos DA, Matos YST, Oliveira-Junior MC, Oliveira LVF, da Palma RK, Candeo LC, Lino-Dos-Santos-Franco A, Horliana ACRT, Gimenes Júnior JA, Aimbire F, Vieira RP, Ligeiro-de-Oliveira AP (2018) Low-level laser therapy reduces lung inflammation in an experimental model of chronic obstructive pulmonary disease involving P2X7 receptor. Oxid Med Cell Longev 2018:6798238. https://doi.org/10.1155/2018/6798238

26. de Brito AA, da Silveira EC, Rigonato-Oliveira NC, Soares SS, Brandao-Rangel MAR, Soares CR, Santos TG, Alves CE, Herculano KZ, Vieira RP, Lino-Dos-Santos-Franco A, Albertini R, Aimbire F, de Oliveira AP (2020) Low-level laser therapy attenuates lung inflammation and airway remodeling in a murine model of idiopathic pulmonary fibrosis: Relevance to cytokines secretion from lung structural cells. J Photochem Photobiol B 203:111731. https://doi.org/10.1016/j.jphotobiol.2019.111731

27. Alves WE, Tim CR, Martignago CCS, Liebano RE, Gomes RS, Assis L (2020) Verification of the effects of red light-emitting diode therapy on acute lung injury in a sepsis model in rats Braz. arch. biol. Technol. 63: e20180668. https://doi.org/10. 1590/1678-4324-2020180668

28. Amirov NB (2002) Pokazateli membrannor̆ pronitsaemosti, mikrotsirkuliatsii, funktsii vneshnegio dykhaniia i soderzhanie mikroélementov pri medikamentozno-lazernoŭ terapii pnevmonii [Parameters of membrane permeability, microcirculation, external respiration, and trace element levels in the drug-laser treatment of pneumonia]. Ter Arkh;74(3):40-3. Russian. PMID: 11980120.

29. Erkinovna, TB; Tulkunovna, MH (2016) Efficacy of laser therapy in infants with infectious-inflammatory respiratory diseases. European science review, 1-2.

30. Ostronosova NS (2006) [Outpatient use of laser therapy in bronchial asthma]. Ter Arkh 78(3):41-4. Russian. PMID: 17019957.

31. Herrera MT, Toledo C, Valladares F, Muros M, Díaz-Flores L, Flores C, Villar J (2003) Positive end-expiratory pressure modulates local and systemic inflammatory responses in a sepsisinduced lung injury model. Intensive Care Med 29(8):1345-1353. https://doi.org/10.1007/s00134-003-1756-5

32. Matute-Bello G, Downey G, Moore BB, Groshong SD, Matthay MA, Slutsky AS, Kuebler WM (2011) Acute lung injury in animals study group. An official American Thoracic Society workshop report: features and measurements of experimental acute lung injury in animals. Am J Respir Cell Mol Biol 44(5):725-38. https://doi.org/10.1165/rcmb.2009-0210ST7 
33. Yin K, Wilmanski J, Wang C, Qiu G, Tahamont M (2000) Lung compartmentalization of inflammatory cells in sepsis. Inflammation 24(6):547-557. https://doi.org/10.1023/a:1007077407302

34. Sheu CC, Gong MN, Zhai R, Bajwa EK, Chen F, Thompson BT, Christiani DC (2010) The influence of infection sites on development and mortality of ARDS. Intensive Care Med 36(6):963-970. https://doi.org/10.1007/s00134-010-1851-3

35. Aimbire F, Albertine R, de Magalhães RG, Lopes-Martins RA, Castro-Faria-Neto HC, Zângaro RA, Chavantes MC, Pacheco MT (2005) Effect of LLLT Ga-Al-As (685 nm) on LPS-induced inflammation of the airway and lung in the rat. Lasers Med Sci 20(1):11-20. https://doi.org/10.1007/s10103-005-0339-9
36. Aimbire F, Ligeiro de Oliveira AP, Albertini R, Corrêa JC, Ladeira de Campos CB, Lyon JP, Silva JA Jr, Costa MS (2008) Low level laser therapy (LLLT) decreases pulmonary microvascular leakage, neutrophil influx and IL-1beta levels in airway and lung from rat subjected to LPS-induced inflammation. Inflammation 31(3):189-197. https://doi.org/10.1007/s10753-008-9064-4

Publisher's Note Springer Nature remains neutral with regard to jurisdictional claims in published maps and institutional affiliations. 